\title{
Desenvolvimento sustentável e o ecoturismo em Unidades de Conservação: discussões sobre o Parque Estadual do Jalapão (TO)
}

\section{Sustainable development and the ecotourism in Protected Areas: discussions about Jalapão State Park (TO, Brazil)}

\author{
Erick da Silva Santos, Edilene Adelino Pequeno, Khalla Tupinamba Ribeiro, \\ Letícia Lima de Freitas
}

\begin{abstract}
RESUMO
A utilização sustentável dos recursos naturais consolidou-se como um dos maiores problemas da atualidade, gerando embates e debates desde a escala local até à global, sendo este o maior desafio do terceiro milênio. Entre os mecanismos encontrados para a proteção do patrimônio natural está a criação de Unidades de Conservação da Natureza, cujo manejo divide-se em doze categorias, entre essas o Parque destaca-se como a categoria mais procurada por visitantes. Assim, constitui objetivo do presente artigo discutir a utilização do Parque Estadual do Jalapão (PEJ), para a recreação, práticas de aventura e ecoturismo, bem como a forma que tais atividades têm ocorrido. Ao longo dos 14 anos de criação, o PEJ tem experimentado um vertiginoso crescimento na visitação pública, ao ponto que transcendeu do anonimato para o reconhecimento no âmbito nacional e internacional, servindo de cenário para realização de reality show, eventos esportivos, documentários, reportagens e foi considerado um dos dez destinos no Brasil que fizeram o país levar o título de melhor destino de aventura 2009 pela prestigiada revista National Geographic Adventure. A metodologia deste estudo aborda a pesquisa qualitativa e em conformidade com o objetivo deste, trata-se de um estudo exploratório-descritivo. Quanto aos procedimentos técnicos, apresenta-se uma pesquisa documental, bibliográfica e de campo, esta última com entrevistas realizadas junto aos moradores locais e instituições públicas. Para coleta de dados também foi utilizado o clipping, técnica da comunicação social. Para análise, foram aplicadas técnicas qualitativas, conforme o objetivo da pesquisa e os tipos de dados coletados, tais como: análise crítica e descritiva. Como resultados principais, verificamos que a visitação pública vem ocasionando dissonâncias entre os objetivos de criação do Parque e o próprio princípio do desenvolvimento sustentável, com impactos socioambientais indesejáveis.
\end{abstract}

KEYWORDS: Ecoturismo; Unidades de Conservação; Impactos; Visitação; Parque Estadual do Jalapão. 


\section{ABSTRACT}

Sustainable use of natural resources has become one of the biggest problems of our time, producing conflicts and debates from local to global scales, and this is the ultimate challenge of the third millennium. The Protected Areas was one mechanism created to protect the natural heritage. Its management is divided into twelve categories and the Park one is the most sought by visitors. So, we aim to discuss the use of Jalapão State Park (PEJ) for recreational, adventure and ecotourism practices, and the way that such activities have been conducted. Over the 14 years of its creation, PEJ has experienced a rapid public visitation growth to the point that transcended from anonymity to national and international recognition, serving as the background for reality shows, sporting events, documentaries, reports and so on. In addition, the Park was between the top ten destinations in Brazil that pushed the country up to be awarded as the Best Adventure Destination in 2009 recognized by the prestigious magazine National Geographic Adventure. The methodology includes qualitative research in accordance with the objectives. This comprises an exploratory-descriptive study, technical procedures, documentary research, literature, fieldwork and interviews with local residents and public institutions. For data collection was also used the clipping, a communication technique. For analysis, qualitative techniques were applied according to the research objectives and the types of data collected, such as critical and descriptive analysis. The main results found that the public visitation has caused dissensions among creative goals of the Park and the principle of sustainable development, causing environmental impacts.

KEYWORDS: Ecotourism; Protected Areas; Impacts; Visitors; Jalapão State Park.

\section{Introdução}

O expressivo aumento da população mundial que passou de pouco mais de 1 bilhão de habitantes no fim do século XIX para mais de 7 bilhões no início do século XXI, bem como a definitiva consolidação do capitalismo como sistema econômico, contribuiu sobremaneira para o inchamento das cidades através da industrialização e busca de empregos, o que provocou uma nova mudança no contexto social mundial, levando a população predominantemente residente no meio rural para o mundo urbano e indústrializado, repleto de demandas por produtos e serviços (UNDESA, 2010).

O aglomerado das habitações em cidades facilitou 0 uso de tecnologias como energia elétrica, água encanada, pavimentação de vilas, entre outras, levando a uma transformação na organização social que provocou novas demandas tais como criação de hospitais, escolas, meios de transporte e de comunicação. Associando-se a isso, o aumento da capacidade humana de apreensão de bens naturais, assim como a multiplicação de possibilidades para seu uso, fez com que a população humana requeresse cada vez mais recursos provenientes da natureza.

Dessa forma, o homem deixou de ser um simples coletor/caçador, passando por agricultor, pastor, artesão, comerciante para chegar ao industrial e atual homem moderno, com todos os seus erros e acertos. (GUAPYASSÚ, 2004, p.2). Advinda dessa "modernidade", que industrializou a agropecuária, criou meios mais eficazes de pesca, dominou a extração de combustíveis fósseis, inventou veículos potentes e revolucionou os meios de transporte com a invenção dos aviões, vieram os defensivos agrícolas, a 
construção de barragens e canais de irrigação, a contaminação pela intensa extração de minérios, o desmatamento para obtenção de madeira, carvão e espaço para a agricultura, a poluição e assoreamento de rios, poluição de águas pelas indústrias, a emissão de gases poluentes na atmosfera e a extinção de espécies.

Todo este processo acarretou numa preocupação (de forma mais enérgica a partir de 1970) sobre até que ponto as ações humanas interfeririam no equilíbrio do ecossistema do planeta, afetando sobremaneira sua biodiversidade. Biodiversidade essa que tem sido amplamente afetada pelas ações ou "evolução" humana. Fontes (2003, p. 9) revela que, dos cerca de 5 a 30 milhões de espécies que se acredita ter no planeta, somente em torno de 1,4 milhão de organismos foram descritos, o que comprova o elevado grau de desconhecimento humano em relação à diversidade da Terra. Algumas estimativas chegam a alcançar 100 milhões o número de espécies no globo (MAY, 2010).

As atuais taxas de extinção, conforme os estudos de Pimm (2005) relatados em seu livro Terras da Terra: $O$ que sabemos sobre o nosso planeta, chegam a ser de uma espécie por ano para cada 10.000 espécies, cem vezes mais do que seria considerado normal. Se analisados os números atuais de espécies ameaçadas, as contas podem chegar a uma espécie para cada 1.000, elevando para 1.000 vezes além do normal.

Santos (2007) afirma que este processo pode ser compreendido (porém não aceitável) ao analisar um dos mais completos documentos elaborados sobre a real situação do meio ambiente na Terra: o relatório da Avaliação Ecossistêmica do Milênio. Encomendado pela Organização das Nações Unidas - ONU, o balanço concluiu que

\begin{abstract}
Uma das maiores barreiras à proteção do capital natural é a ignorância sobre os serviços que este capital provê. A abordagem da Avaliação Sistêmica do Milênio, já sendo usada em diversos estudos em escala local e regional, pode oferecer uma ferramenta útil para os tomadores de decisão compreenderem melhor as consequências de seus atos (MILLENNIUM ECOSYSTEM ASSESSMENT, 2005, p. 30).
\end{abstract}

Infere-se do texto acima que os maiores problemas enfrentados em relação aos impactos negativos ao meio ambiente natural é justamente a falta de conhecimento em relação aos reais efeitos danosos que as ações humanas podem provocar, corroborando sobremaneira com a importância do planejamento em todas as questões que se envolve a natureza, além da criação de mais áreas protegidas para garantir que ao menos seja possível descobrir com maior profundidade sobre os serviços que o patrimônio natural pode fornecer.

Guapyassú (2004, p.13) ainda revela a existência bastante estreita entre as características do ecossistema, sua capacidade de suporte, os mecanismos de auto regulação e de absorção de impactos e sua capacidade de reagir às ações degradadoras. Isto significa que a "quebra" destes mecanismos ou a super exploração dos recursos além do que podem 
suportar, interfere em todo o processo do sistema ecológico, acarretando nas atuais consequências climáticas: chuvas torrenciais, rios abundantes sendo castigados pelas secas intensas, aquecimento com acidificação dos oceanos, perda de diversidade biológica, intensificação de ciclones, entre outros (TRUMPER et al., 2009; IPCC, 2007).

E neste meio intenso e conturbado de como criar mecanismos de proteção à natureza, surgem uma das ferramentas primordiais para auxiliar no combate a esta ignorância ao conhecimento do capital natural do planeta, as Unidades de Conservação (UC) da natureza, que determinam áreas para a preservação do meio ambiente e possibilitam a educação e sensibilização ambiental bem como estudos e pesquisas científicas. Seguindo este cenário de políticas públicas foi que surgiu a criação do Parque Estadual do Jalapão, no Estado do Tocantins, consolidando a instituição do Sistema Nacional de Unidades de Conservação da Natureza (SNUC).

Considerando que o ecoturismo é uma especialização multifacetada do turismo, mostrando-se como ferramenta para a conservação de ambientes naturais ao mesmo tempo em que pode causar conflitos de uso do patrimônio natural, o presente trabalho tem como objetivo discutir a utilização do Parque Estadual do Jalapão, UC de proteção integral categoria Parque, para a recreação, práticas de aventura e ecoturismo, bem como a forma que tais atividades têm ocorrido. A escolha do Parque deveu-se à sua importância para a biodiversidade e ao forte apelo para a visitação pública demonstrado massivamente pela mídia nos últimos anos, ocasionado uma série de demandas de realização de eventos dentro da UC que conflitam com os objetivos de proteção da natureza para o qual foi criado, não condizentes, também, com a verdadeira prática do ecoturismo.

\title{
Ecoturismo e Unidades de Conservação
}

Para um bom entendimento sobre o tema, e segundo a legislação brasileira dada por meio da Lei n. 9.985/00 que dispõe sobre o Sistema Nacional de Unidades de Conservação da Natureza (SNUC), as Unidades de Conservação (UCs) - mundialmente conhecidas como Áreas Protegidas - são conceituadas como:

\begin{abstract}
espaço territorial e seus recursos ambientais, incluindo as águas jurisdicionais, com características naturais relevantes, legalmente instituído pelo poder público, com objetivos de conservação e limites definidos, sob regime especial de administração, ao qual se aplicam garantias adequadas de proteção (MMA, 2004, p. 9).
\end{abstract}

Continuando, conforme a mesma legislação, existem doze categorias de manejo reunidas em dois grupos distintos. A categoria Parque, juntamente com outras quatro categorias, pertence ao conjunto de unidades de conservação de proteção integral, enquanto que as UCs de uso sustentável totalizam sete categorias (MMA, 2004, p. 16). Neste trabalho aborda-se apenas o conceito da categoria Parque, uma vez que esse é o objeto de estudo desta pesquisa. 
Dado pelo Art. 11 da referida Lei, o Parque Nacional tem posse e domínio públicos, e prevê que as áreas particulares incluídas nos seus limites devem ser desapropriadas. Diz ainda que:

\begin{abstract}
Parque Nacional tem como objetivo básico a preservação de ecossistemas naturais de grande relevância ecológica e beleza cênica, possibilitando a realização de pesquisas científicas e o desenvolvimento de atividades de educação e interpretação ambiental, de recreação em contato com a natureza e de turismo ecológico (MMA, 2004, p. 9).
\end{abstract}

O turismo ecológico surgiu na década de 80 como uma ferramenta que vislumbrava 0 desenvolvimento sustentável nos países em desenvolvimento. Porém o SNUC explicita que a visitação pública nos Parques está sujeita às normas e restrições estabelecidas no Plano de Manejo da unidade, e às normas estabelecidas pelo órgão responsável por sua administração, bem como àquelas previstas em regulamento específico.

O termo ecoturismo, de acordo com Wearing e Neil (2001), deriva da redução da expressão "turismo ecológico", empregada pela primeira vez em 1981 por Hector Ceballos-Lascuráin para exprimir a atividade turística que incluía as viagens para áreas naturais em busca de apreciação do meio ambiente e das culturas visitadas. $\mathrm{O}$ conceito dos autores propõe que $\mathrm{O}$ ecoturismo se trata de

uma área especializada do turismo que inclui viagens para áreas naturais, ou áreas onde a presença humana é mínima, em que o ecoturista envolvido na experiência externa uma motivação explícita de satisfazer sua necessidade por educação e consciência ambiental, social e/ou cultural por meio de visita à área e vivência nela (WEARING; NEIL, 2001, p. 5).

Western (2001) apresenta a definição de ecoturismo sugerida pela Sociedade de Ecoturismo, sendo "a viagem responsável a áreas naturais, visando preservar o meio ambiente e promover o bem-estar da população local". No Brasil, uma reunião do Grupo de Trabalho Interministerial em Ecoturismo, que reuniu vários órgãos como IBAMA, Ministério do Meio Ambiente, Ministério da Indústria, Comércio e Turismo, Embratur e entidades afins, chegou à seguinte conceituação

segmento da atividade turística que utiliza, de forma sustentável, o patrimônio natural e cultural, incentiva sua conservação e busca a formação de uma consciência ambientalista através da interpretação do ambiente, promovendo o bem-estar das populações envolvidas (EMBRTUR, 1994, p. 19).

Conforme observado, o ecoturismo despontou como uma forte estratégia para colaborar na preservação dos recursos naturais, propiciar 
recreação, educação e sensibilização ambiental para a sociedade e ainda gerar divisas às comunidades locais e tradicionais. Em muitos casos, ele se torna uma ferramenta bastante importante para ajudar na preservação, pois além de permitir o contato humano com a natureza e seu entendimento através da interpretação ambiental, o ecoturismo pode gerar receitas consideráveis para os parques, o que pode ser revertido para a conservação da natureza.

A exemplo cita-se o Parque Nacional do Iguaçu, que no ano de 2012, de acordo com a assessoria do Parque (ASCOM - PARQUE NACIONAL DO IGUAÇU, 2013), quebrou o recorde e recebeu mais de 1,5 milhão de visitantes, gerando uma receita de mais de $R \$ 17$ milhões de reais. Entretanto, o questionamento é se o objetivo de criação das UCs vem sendo alcançado Brasil afora, especialmente as de uso mais restritivo como é o caso dos Parques Nacionais e Estaduais. É a pergunta que se pretende responder no Parque Estadual do Jalapão, objeto de estudo desta pesquisa.

Impactos danosos podem ser advindos da visitação pública. Kinker (2002) caracteriza como efeitos negativos a degradação dos ambientes naturais com acúmulo de lixo e depredação de atrativos com pichações; estresse e afugentamento da fauna em razão de presença humana; descaracterização e perda de valores tradicionais em consequência da homogeneização de culturas; mudança nos hábitos de consumo ou a vulgarização da cultura para vendê-la aos turistas; abandono de práticas tradicionais de vivência em virtude de dependência econômica do ecoturismo; pisoteamento, compactação e erosão de trilhas; e aumento do custo de vida em razão de supervalorização de produtos.

Brasil (2010) detalha que os tipos de visitação pública em um Parque (Nacional, Estadual ou Municipal) variam de acordo com a finalidade de visitação, podendo ser turística, recreativas, ou educacionais, condicionadas ao plano de manejo e regulamento da UC. Preferiu-se utilizar o termo visitante em vez do termo turista por ser mais utilizado pela maioria dos autores, mesmo não havendo uma diferença evidente entre os termos (TAKAHASHI, 1998; CIFUENTES, 1992).

\section{Metodologia}

No que tange a metodologia deste estudo, tem-se uma pesquisa com abordagem essencialmente qualitativa e em conformidade com o objetivo deste, trata-se de um estudo exploratório-descritivo. Quanto aos procedimentos técnicos, apresenta-se uma pesquisa documental, bibliográfica e de campo. Para análise, foram aplicadas técnicas qualitativas, conforme o objetivo da pesquisa e os tipos de dados coletados, tais como: análise crítica e descritiva.

Para constituição deste trabalho, foram efetuadas pesquisas bibliográficas sobre os estudos científicos referentes ao Parque Estadual do Jalapão. Para os dados de visitação houve coleta de dados oficiais com 0 órgão gestor do Parque, Instituto Natureza do Tocantins - NATURATINS e o órgão oficial de turismo, Agência de Desenvolvimento Turístico do Tocantins - ADTur. Em relação ao levantamento de dados relativos aos eventos ocorridos no Parque bem como a investigação das divulgações por meio de 
programas de TV, utilizou-se a técnica da comunicação social, o clipping, o qual consiste na pesquisa, coleta, seleção e fornecimento de material veiculado por meios de comunicação: a imprensa escrita, o rádio, a TV e, mais recentemente, a própria Internet (CROCCO; LOH, 2010).

Para levantamento dos impactos ambientais existentes foram utilizados estudos efetuados sobre impactos da visitação no Jalapão. Relatos de moradores e gestores do Parque também contribuíram para a coleta de dados relativos aos problemas sociais, pois no município de Mateiros não existe serviço de segurança pública como delegacia de polícia que executa registros de tráfico de entorpecentes ou a existência de furtos. A análise dos relatos, levou em consideração os estudos de Krippendorf (1989) que trata das relações entre visitante e visitado e Lickorish e Jenkins (2000) que ressaltam sobre as possiblidades que turismo tem de transformar os hábitos sociais locais por meio da perturbação das normas já estabelecidas pela população local.

Referente ao período das gravações do programa Survivor foram coletados relatos dos moradores e do gestor do Parque na época (entre dezembro de 2009 e junho de 2010). A escolha dos moradores foi efetuada conforme indicação dada pelo gestor do Parque, que identificou lideranças e mesmo aqueles que prestam serviço diretamente com ao visitante, como pousadas e restaurantes.

Para o levantamento dos impactos de geração de renda no turismo, destacam-se as análises feita por Takasago et al. (2010) que demonstram o potencial gerador de emprego e renda no turismo por meio da matriz de insumo-produto. Assim, o aumento na geração de renda de uma localidade pode ser comprovado pelo simples fato do aumento no número vagas de trabalho (formal ou informal) geradas.

\section{Caracterização e importância da área em estudo}

Criado pela Lei Estadual № 1.203 de 12 de janeiro de 2001, o Parque Estadual do Jalapão (PEJ), localizado no extremo leste do Estado do Tocantins, possui uma extensão territorial de 158.885 hectares, dos quais $100 \%$ estão inseridos nos limites do município de Mateiros (TOCANTINS, 2003). A cidade de Mateiros fica a cerca de $370 \mathrm{~km}$ da capital Palmas e o município contém uma totalidade de cerca de 2.223 habitantes, sendo cerca de $40 \%$ moradores da zona rural (IBGE, 2015). O acesso ao Parque se dá por três vias sendo a rodovia TO-110 que vem do município de São Félix e a rodovia TO-255 que liga Ponte Alta do Tocantins à Bahia, passando pelo Parque e por Mateiros (Figura 1).

O Parque possui como bioma predominante o Cerrado. Para se dimensionar a relevância mundial da região onde se encontra, destaca-se que o Cerrado brasileiro está dentre as 34 áreas prioritárias para a conservação no planeta, os chamados hotspots da biodiversidade $(\mathrm{Cl}$, 2013).

Não obstante, sua localização fica numa das áreas de Cerrado mais bem preservado do país, pois faz parte de um conjunto de Unidades de Conservação (UCs) que formam um mosaico em que estão agregados 0 
Parque Nacional das Nascentes do Rio Parnaíba, a Área de Proteção Ambiental (APA) Serra da Tabatinga, a APA Jalapão e a Estação Ecológica Serra Geral do Tocantins, que juntos totalizam mais de 2 milhões de hectares em áreas protegidas. A Figura 1 apresenta uma localização precisa do PEJ no Estado, bem como das demais UCs.

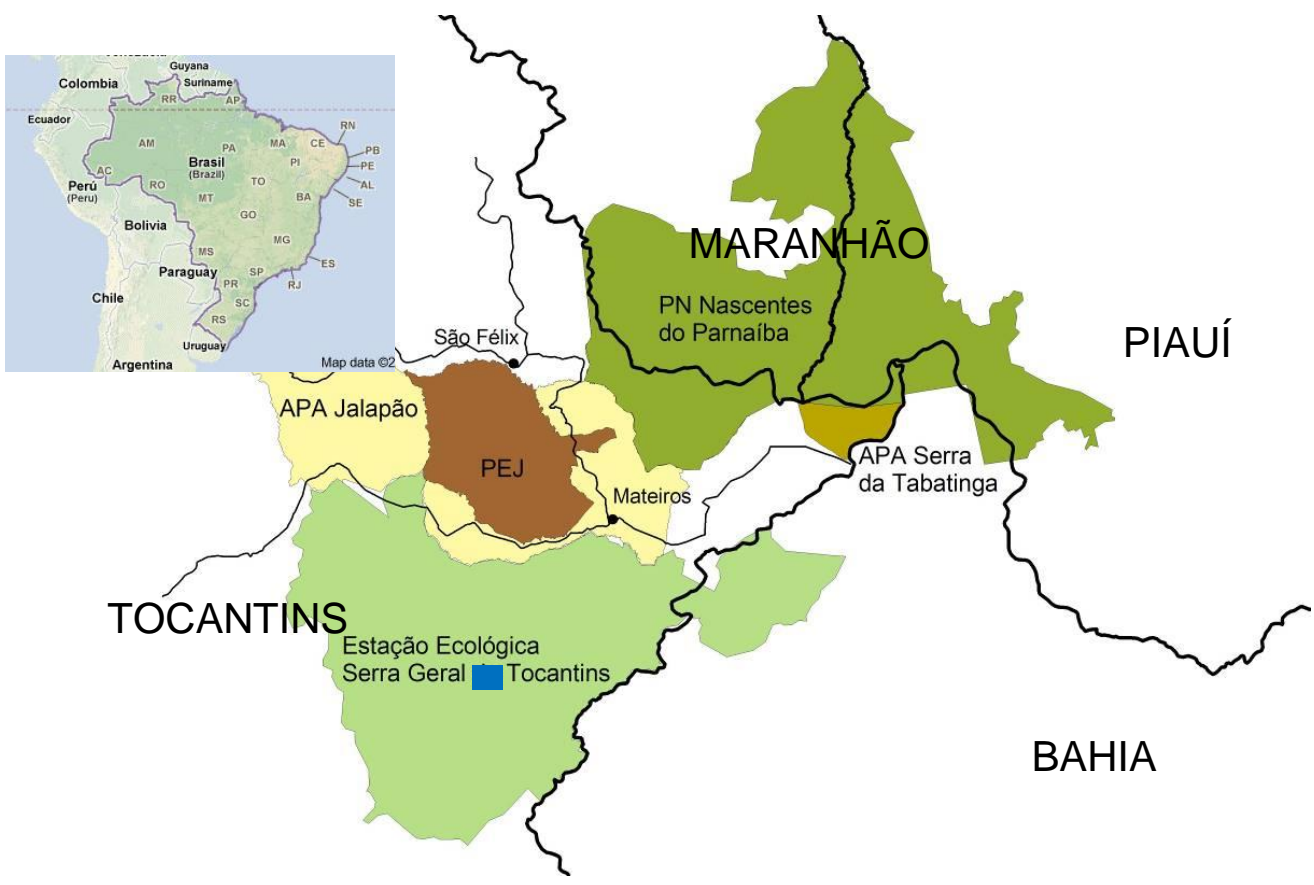

Figura 1: Mapa de localização do PEJ (Parque Estadual do Jalapão) no Estado do Tocantins e as demais Unidades de Conservação que fazem parte do mosaico.

Fonte: resultado da pesquisa.

Figure 1: Location map PEJ (Jalapão State Park) in the State of Tocantins and other Protected Areas that are part of the mosaic. Source: search result.

Referente à biodiversidade do Parque Estadual do Jalapão o Plano de Manejo da UC destaca o registro de 56 espécies de mamíferos, entre as quais dez são consideradas raras, 214 espécies de aves, das quais doze são endêmicas do Cerrado e nove estão ameaçadas de extinção, 25 espécies de anfíbios, 51 espécies de répteis e 464 espécies de plantas. Em relação à ictiofauna do PEJ, o documento não registra a quantidade $e$ espécies de peixes, pois osomantamentos sistemáticos da fauna aquática são inexistentes (TOCANTINS, 2003).

Além dos fatores anteriormente relacionados, o PEJ apresenta em seus limites uma quantidade significativa de nascentes $e$ bacias hidrográficas, dentre as quais estão os principais tributários do Rio Tocantins (principal rio do Estado juntamente com o Rio Araguaia), o Rio Sono e o Rio Novo (Figura 2). A região é reconhecida no cenário nacional como importante recarga do Sistema Aquífero Urucuia (GASPAR, 2006).

Não obstante, o Parque também é habitat de uma espécie criticamente ameaçada de extinção, o Pato-Mergulhão (Figura 3) ou Mergus octosetaceus (BIRDLIFE, 2013). Uma ave que os pesquisadores estimam haver somente 250 indivíduos da espécie em todo o planeta e que, atualmente, acreditam ocorrer em apenas três locais: Parque Nacional Serra 
da Canastra, Parque Nacional Chapada dos Veadeiros e Parque Estadual do Jalapão (IBAMA, 2006).

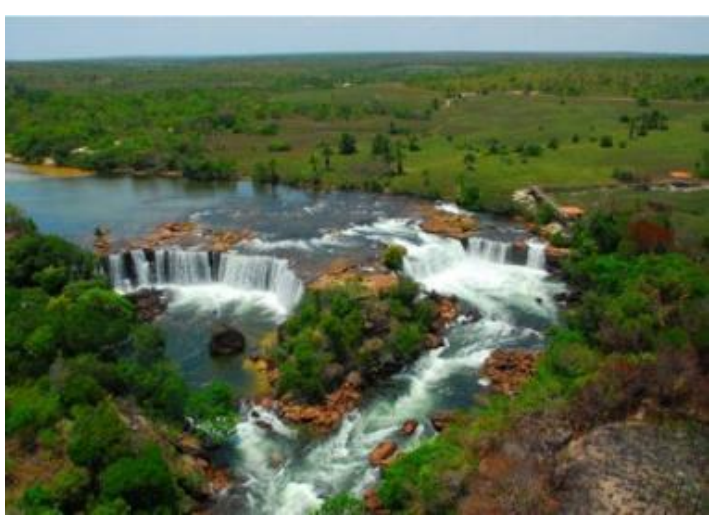

Figura 2: Rio Novo com a Cachoeira da Velha. Fonte: ADTur.

Figure 2: New River with the Old Waterfall . Source : ADTur.

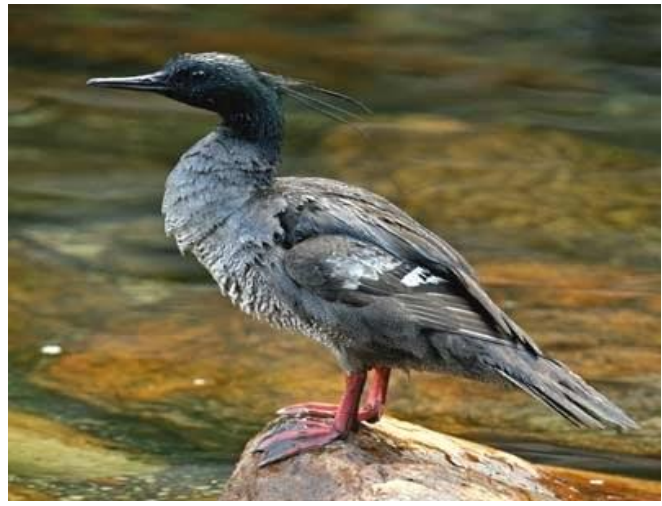

Figura 3: Pato-mergulhão.

Fonte: IECOS Brasil.

Figure 3: Merganser.

Source: IECOS Brazil.

Há ainda, a presença de outras espécies de animais ameaçadas de extinção na lista da BirdLife (2013) como o lobo-guará (Chrysocyon brachyurus), a onça-pintada (Panthera onca), a Suçuarana (Puma concolor), a Jaguatirica (Leopardus pardalis), o Tatu-Canastra (Priodontes maximus), o Tamanduá-Bandeira (Myrmecophaga tridactyla), o Cervo-do-pantanal (Blastocerus dicothomus), a Inhambu-carapé (Taoniscus nanus), a Araraazul-grande (Anodorhynchus hyacinthinus), os lagartos (Iguana iguana, Tupinambis duseni e Tupinambis quadrilineatus), as serpentes (Boa constrictor, Corallus hortulanus, Epicrates cenchria, Eunectes murinus) e o jacaré (Paleosuchus palpebrosus).

O Parque e seu entorno abrigam também, espécies vegetais que contribui sobremaneira para a geração de renda e consequente sobrevivência de boa parte das comunidades tradicionais da região. $O$ Capim-Dourado (Syngonanthus nitens), o Buriti (Mauritia flexuosa), conforme Figuras 4 e 5 , entre outros recursos utilizados em menor escala são fundamentais para gerar renda e garantir o sustento por meio da venda direta aos visitantes de artesanatos e produtos da flora (TOCANTINS, 2003).

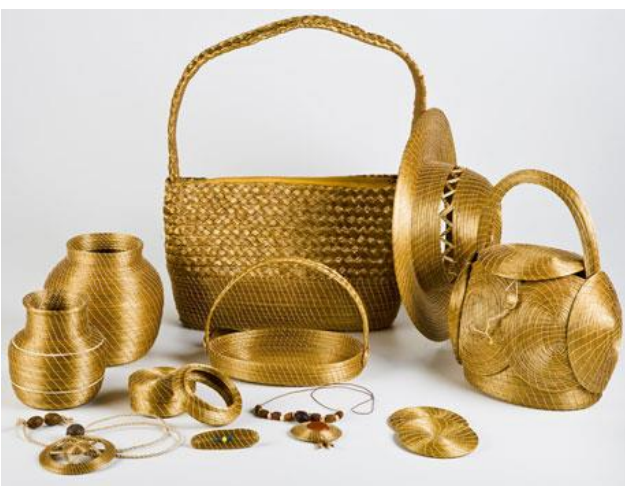

Figura 4: Artesanato de capim dourado.

Fonte: Associação de Artesãos do Jalapão.

Figure 4: Golden grass crafts. Source: Associação de Artesãos do Jalapão.

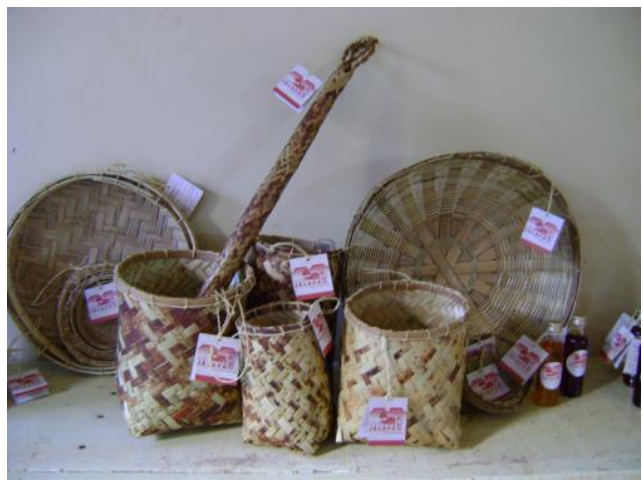

Figura 5: Artesanato de buriti. Fonte: www.oncadagua.org.br.

Figure 5: Buriti Crafts.

Source: www.onçadagua.org.br. 
Pela caracterização apresentada da área pode-se perceber a importância biológica do Parque e também seu papel enquanto promotor do desenvolvimento sustentável, provendo comunidades tradicionais de renda por meio da venda direta do artesanato de capim dourado aos visitantes, fonte primária da economia de muitas famílias da região, especialmente da comunidade Mumbuca, precursora da técnica e que hoje experimenta uma transformação em seu modo de produção econômica. A força do capim dourado ultrapassou as fronteiras brasileiras e atingiu 0 cenário internacional, com vendas em Portugal, França e Espanha.

\section{Resultados e discussões}

\section{Do anonimato ao reconhecimento internacional}

Conforme relatado anteriormente, o Parque Estadual do Jalapão foi criado no ano de 2001. À época, a região era pouco conhecida e quase anônima para a maioria dos próprios moradores do Estado do Tocantins. Mas o Jalapão iniciou sua "carreira" de reconhecimento através das primeiras competições do Rally dos Sertões que por ali passavam. De acordo com levantamentos históricos da corrida, o chamado "Deserto do Jalapão" passou a ser incluído no roteiro a partir do ano de 1999, conforme pode ser observado no mapa do roteiro, na Figura 6 (EMBRAPA, 2013).

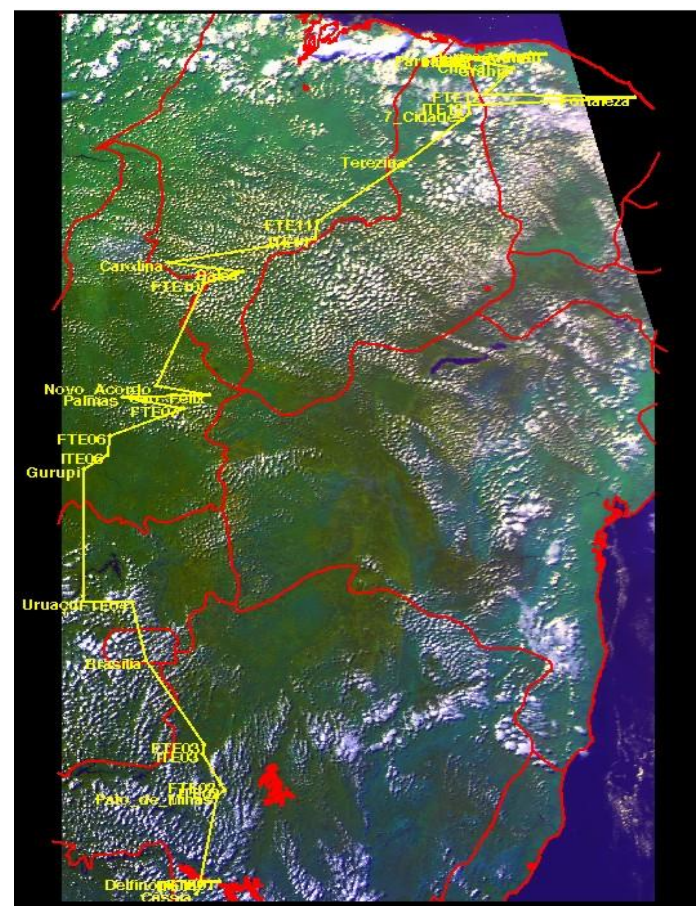

Figura 6: Mapa da rota percorrida no Rally dos Sertões de 1999, iniciando em São Paulo e cruzando os Estados de Minas Gerais, Distrito Federal, Goiás, Tocantins, Maranhão, Piauí e finalizando no Ceará. Fonte: EMBRAPA (2013).

Figure 6: Map of the route taken in the Rally dos Sertões de 1999, starting in São Paulo and across the states of Minas Gerais, Distrito Federal, Goiás, Tocantins, Maranhão, Piauí and Ceará ending. Source: EMBRAPA (2013). 
Neste período, o Parque ainda não havia sido criado. No entanto, tais eventos serviram para lançar as primeiras curiosidades sobre a região, chamada de "Deserto do Jalapão" por ser uma área bastante arenosa e com formações de Dunas (Figura 7).

Nos anos que se seguiram o Rally Internacional dos Sertões foi incorporando cada vez mais categorias (motocicleta, caminhão) e desenvolvendo modalidades de competição distintas. Inserido nesse contexto, a região do Jalapão foi se consolidando como rota definitiva para o evento que, devido ao seu forte apelo midiático, passou a despertar a atenção de outros meios de comunicação em massa.
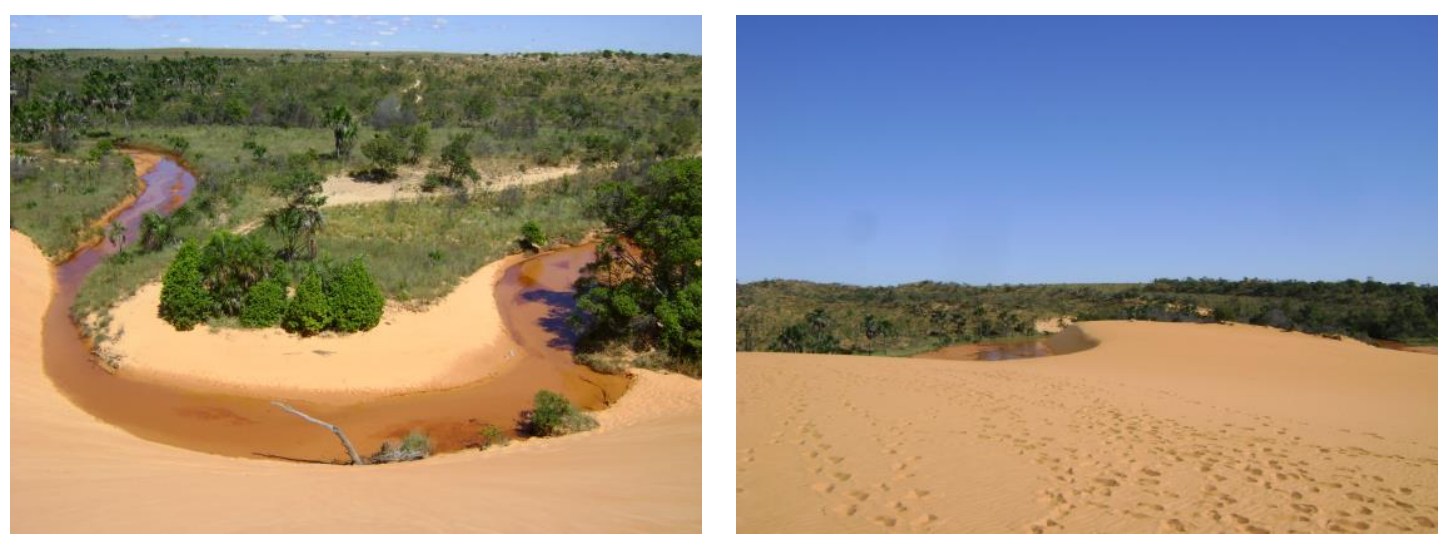

Figura 7: Dunas do Parque Estadual do Jalapão (TO) Brasil. Fonte: arquivo próprio.

Figure 7: State Park Dunes Jalapão (TO) Brazil. Source: own file.

A partir da instalação do Parque em 2001 foram iniciadas as primeiras ações para sua estruturação. Mas as visitas ainda eram esporádicas e 0 local se restringia a poucos que se lançavam a aventurar pela região que não oferecia qualquer infraestrutura. Em 2003, pela primeira vez uma emissora de televisão realiza um programa na região do Jalapão para transmissão em rede nacional.

Em agosto daquele ano, o programa Planeta Turismo, da emissora SBT, levou ao conhecimento do público em geral uma reportagem turística sobre o Jalapão, que tinha como chamada o seguinte texto: "Na edição comemorativa do seu primeiro aniversário, o Planeta Turismo visita o deserto do Jalapão, no Tocantins. A região é formada por dunas, chapadões, cachoeiras, planaltos e savanas" (TV PRESS, 2003).

É com esse slogan de "deserto" no meio do Cerrado brasileiro que a região decolou em direção ao reconhecimento nacional até chegar ao ápice quando o órgão gestor do Parque foi procurado para que o Jalapão fosse cenário de um dos mais famosos reality shows do mundo: o programa americano Survivor.

Antes de aportar no Tocantins, a rede de TV americana CBS já havia gravado edições do programa Survivor em locais como o Gabão, Quênia, Austrália, Ilhas Cook, Tailândia, China, Fiji, Palau, entre outros. Em 2008 o Jalapão recebeu a décima-oitava temporada do reality show que contou com 
a participação de dezesseis norte-americanos. Para se dimensionar o poder de alcance de veiculação do programa, Survivor já atingiu audiências que ultrapassam os 51 milhões (PIERUCCINI, 2009). O último episódio do Survivor Tocantins foi transmitido ao vivo pela CBS em fevereiro de 2009 para mais de 100 países, promovendo a região ao conhecimento internacional (CONEXÃO TOCANTINS, 2009).

Nos anos que se seguiram houve expressivo aumento na demanda de visitação tanto interna quanto de estrangeiros. No feriado da semana de carnaval de 2013, o PEJ recebeu mais de 700 visitantes, contra um total de cerca de 1.650 visitantes anuais que o Parque recebia entre 2006 e 2010 nas estimativas dos estudos de Dutra, Senna, Ferreira \& Adorno (2008) e Naturatins (2013). De acordo com a ADTur (2012) o parque recebeu 5.812 visitantes em 2012 e 16.667 em 2013 (TOCANTINS, 2014). Inexiste no órgão dados do fluxo de visitação anteriores a 2012. Também não há controle de visitação efetuado pelo órgão gestor da UC.

Coincidência ou não, ainda em 2008, no período de gravação do Survivor, a prestigiada revista National Geografic Adventure, com mais de 2,4 milhões de leitores no mundo, elegeu o Brasil como melhor destino de Aventura do mundo. Em seu texto original Best of Adventure 2009, os editores da revista ponderaram as consistentes melhorias em infraestrutura de transporte que o Brasil recebeu para acessar os destinos mais exóticos do país. Entre os dez destinos que fizeram do Brasil o melhor lugar para aventura do mundo estão, além da Amazônia, a Chapada Diamantina, Chapada dos Veadeiros, Chapada dos Guimarães, Fernando de Noronha, Florianópolis, Foz do Iguaçu, Jalapão, Lençóis Maranhenses e Pantanal (WEBVENTURE, 2008).

Embalados pela repercussão do Survivor, em 2009 foi a vez da maior corrida de aventura do país a desembarcar no Parque Estadual do Jalapão, a Brasil Wild Extreme. Uma competição que envolveu mais de 300 participantes que praticaram, entre outras atividades, natação, corrida, técnicas verticais, rafting no Rio Novo e acessou zonas do Parque que são destinadas exclusivamente para a preservação da natureza. Os principais meios de comunicação do Brasil e suas emissoras realizaram a cobertura completa do evento, o qual foi veiculado diversas vezes em vários programas esportivos (BRASIL WILD, 2009).

Para Takahashi (1998), o fato da atividade turística ser "amplamente divulgada através dos meios de comunicação, sempre vinculada à imagem de ação e aventura em áreas naturais, somente contribui para fortalecer uma inadequada relação, qual seja, ecoturismo = aventura".

Continuando a saga de divulgação a nível nacional e internacional, em 2011 o programa de documentários mais conhecido do Brasil, o Globo Repórter, realizou uma reportagem completa sobre o Parque Estadual do Jalapão. Veiculado pela emissora de TV Globo, o programa também foi transmitido a todos os que assistem a Globo Internacional em vários outros países. Apesar da ampla divulgação, o documentário teve caráter bastante científico, mostrando a importância da preservação do território. 


\section{Principais impactos socioambientais}

$\mathrm{Na}$ região do Parque Estadual do Jalapão os principais efeitos danosos encontrados decorridos da visitação, principalmente das gravações do Survivor, (conforme relatos de moradores) foram a introdução de problemas sociais com drogas, pois não havia em Mateiros hábitos com maconha e outros entorpecentes como crack e até cocaína.

De acordo com relatos de moradores, cerca de cinco meses depois das gravações ocorreram furtos de gado por alguns dos jovens da cidade com o objetivo de comprar drogas, transformando hábitos sociais e perturbando as normas ou concepções locais ressaltadas por Lickorish e Jenkins (2000). Outro impacto foi o nascimento de um sentimento de subvalorização, que também se tornou um imperativo entre os moradores e pode ser visto na literatura de Krippendorf (1989). Tal sentimento deveu-se pela estrutura de conforto e aparato tecnológico colocado à disposição da equipe de filmagem durante os quatro meses de gravação. E que causou estranheza na pequena cidade de Mateiros que experimentou uma revolução com internet wi-fi em meio à praça pública numa cidade que possuía somente serviço de internet discada e com poucos locais de acesso.

Não se pode negar, contudo, o aspecto positivo que o turismo pode trazer para as comunidades, como a geração de renda para muitos moradores. A própria comunidade do Mumbuca experimentou uma mudança substancial em sua renda devido às receitas geradas com a venda do artesanato de Capim Dourado e a instalação de uma pousada e restaurante que sustentam uma família de seis pessoas, das quais quatro estão envolvidas no pequeno negócio. Não obstante, uma moradora de Mateiros, dona Rosa, relatou que construirá seu novo restaurante com financiamento próprio devido ao aumento de visitantes na região. Seu estabelecimento emprega mais quatro pessoas e é o sustento de sua família.

Em relação aos impactos ambientais, ressalta-se a sobrecarga dos espaços destinados à visitação, não respeitando a capacidade de suporte da natureza. O legado deixado pelo Rally dos Sertões constitui-se de erosões e voçorocas que chegam a $10 \mathrm{~m}$ de largura e quase $300 \mathrm{~m}$ de extensão (Figura 8).

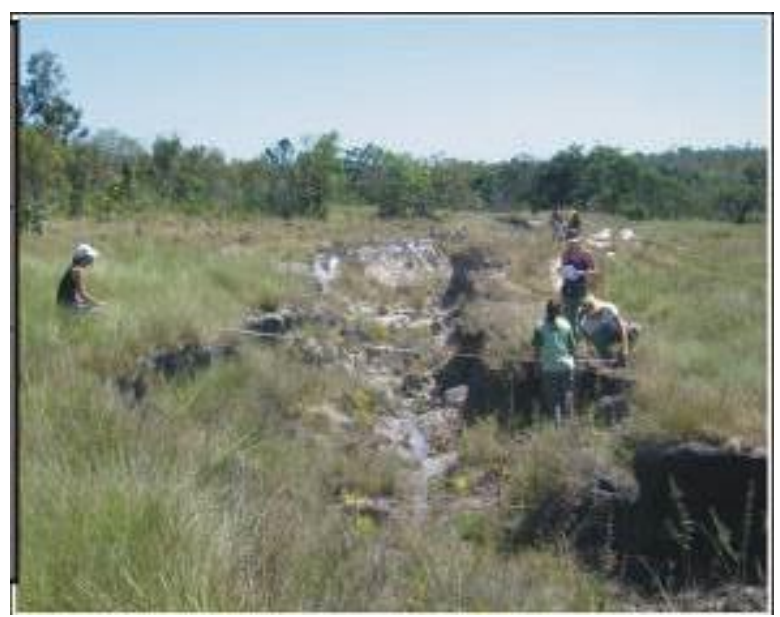

Figura 8: Voçorocas provocadas pela passagem de carros. Fonte: Adorno (2008).

Figure 8: Gullies caused by passing cars. Source: Adorno (2008). 
A corrida de aventura Brasil Wild Extreme, com mais de 300 participantes, acessou zonas intangíveis dentro do PEJ, ou seja, áreas que são destinadas unicamente para preservação, o que gerou pisoteamento com degradação do solo em áreas de vereda (áreas húmidas) e possivelmente ocasionou distúrbios ao único habitat do Pato-mergulhão no Jalapão devido à realização de rafting no Rio Novo, espécie muito sensível à presença humana (ALMEIDA, 2013).

A organização do evento intitulava a competição como "a corrida da sustentabilidade", pois acreditava que ao contratar mais de 90 pessoas nas quatro cidades onde ocorreu o circuito estariam sendo sustentáveis, pois além de gerar renda transmitiriam know-how para tais pessoas. Tais afirmações representam a distorção e banalização do termo desenvolvimento sustentável, que tem em seu princípio a manutenção dos ecossistemas, a geração de renda para comunidades locais e conservação das culturas tradicionais (SACHS, 1986; BRUNDTLAND, 1987).

\section{Considerações finais}

O presente trabalho objetivou discutir a forma como o Parque Estadual do Jalapão tem sido utilizado. Os resultados mostraram que o Parque enfrenta um problema da falta de controle de visitação e o fato do governo apoiar eventos no Jalapão inseriu uma preocupação sobre o futuro da gestão da UC, uma vez que o PEJ é um dos poucos locais ainda bem protegidos em toda região do Cerrado brasileiro, com potencial de permitir a conservação e permanência de populações de fauna e flora que estão sob intensa pressão em outros locais do país. Conforme discorrido anteriormente, o principal objetivo da criação de um Parque é a conservação da biodiversidade, mas o que tem ocorrido é a priorização da divulgação em massa de um destino de aventura despreparado e desprovido de infraestrutura para receber fluxos de visitação intensos.

Dessa forma, urge a formatação de um plano de controle da visitação pública para o Parque considerando o que Eagles, McCool e Haynes (2002) orienta: a tomada de decisão no âmbito da gestão do turismo em Unidades de Conservação deve envolver muito além dos gestores das áreas, pois afeta também a comunidade local, os visitantes, as operadoras de turismo e os cientistas pesquisadores.

No caso específico do Jalapão, os resultados apresentados permitem concluir que a região é caracterizada por um turismo de aventura com princípios sustentáveis deturpados, necessitando redirecionar a atividade para o ecoturismo, que pode trazer muitos benefícios ao Parque e às comunidades locais, com mínimo impacto aos ambientes. Porém, caso a atividade turística esteja restrita à busca de aventuras e "rallies", sem interesse e comprometimento com as peculiaridades ambientais e sociais da região, pode trazer impactos irreversíveis ao PEJ. A sociedade e, principalmente, os órgãos responsáveis pela gestão da UC devem ter o compromisso e o senso de responsabilidade social e ambiental que fundamentam a atividade de ecoturismo. 
Tal como está organizado não há razão para utilizar o termo ecoturismo em substituição ao tradicional turismo. Afinal, o ecoturismo pode sim ser uma ferramenta de conservação da UC por valorizar a natureza por meio da intepretação e sensibilização ambiental. O que se faz urgente é o controle e manejo correto da visitação e dos usuários que buscam o Parque para fins de aventura. Sugere, ainda, que o órgão gestor do Parque atentese para a consolidação de uma instância de governança que norteie e delibere sobre a utilização dos recursos existentes nos limites da UC.

\section{Referências bibliográficas}

ADORNO, L.F M. Turismo no Parque Estadual do Jalapão: Identificação dos usos e proposição de medidas de controle e monitoramento. Relatório Técnico. Curitiba: Fundação Grupo O Boticário, 2008. 162 p.

ADTUR. Agência de Desenvolvimento Turístico do Tocantins. Perfil da demanda turística da fazenda Triago - Cachoeira da Velha e prainha do rio Novo. Palmas, dez. 2012.

ALMEIDA, M.L. Distribuição e conservação do pato mergulhão no Jalapão - Tocantins. Relatório Técnico Conclusivo de Projeto. Palmas: Instituto Ecos do Cerrado Brasil, 2013. 135 p.

ASCOM - Assessoria de Comunicação do Parque Nacional do Iguaçu. Cataratas do Iguaçu S.A. 2013. Disponível em http://www.cataratasdoiguacu.com.br/portal/ paginas/310-parque-nacionaldo-iguacu-fecha-2012-com-mais-de-1,5-milhao-de-visitantes.aspx. Acesso em 3 de Agosto 2013

BIRDLIFE INTERNATIONAL. Mergus octosetaceus. The IUCN Red List of Threatened Species. Version 2014.3. 2013. Disponível em: http://www.iucnredlist.org/details/22680482/0. Acesso em 28 fev. 2015.

BRASIL WILD. Brasil wild extreme 2009. a Corrida. 2009. Disponível em http://www.brasilwild.com.br/extreme2009cobertura/corrida.asp. Acesso em 18 de Maio de 2013.

BRASIL. Ministério do Turismo. Ecoturismo: orientações básicas. Secretaria Nacional de Políticas de Turismo, Departamento de Estruturação, Articulação e Ordenamento Turístico, Coordenação Geral de Segmentação. 2. ed. Brasília: Ministério do Turismo, 2010. 90p.

BRUNDTLAND, G.H. Our common future. Report of the World Commission on Environment and Development. United Nations: Oslo, 1987.

$\mathrm{Cl}$ - Conservation International. The biodiversity hotspots. South America. Cerrado. 2013. Disponível em http://www.conservation.org/where/priority areas/hot spots/south america/Cerrado/Pages/default.aspx. Acesso em 12 de maio de 2013.

CIFUENTES, M. Determinación de capacidad de carga turística em áreas protegidas. Turrialba: Catie, 1992. p.18-35. 
CONEXÃO TOCANTINS. Vencedor do Survivor quer voltar ao Tocantins. 2009. Disponível em http://conexaoto.com.br/2009/05/18/vencedor-dosurvivor-quer-voltar-ao-jalapao. Acesso em 12 de Maio de 2013.

CROCCO, G; LOH, S. Agrupamento de textos por similaridade para sistema de clipping web: clusterclipping. Universidade Luterana do Brasil: Canoas, 2010.

DUTRA, V.C.; SENNA, M.L.G.S.; FERREIRA, M.N.; ADORNO, L.F.M. Caracterização do perfil e da qualidade da experiência dos visitantes no Parque Estadual do Jalapão, Tocantins. Caderno Virtual de Turismo. v. 8, n.1, p.104-117, 2008.

EAGLES, P. F. J.; MCCOOL, S. F.; HAYNES, C. D. A. Sustainable tourism in Protected Areas: Guidelines for planning and management. IUCN Gland, Switzerland and Cambridge, UK, 2002. 183p.

EMBRAPA. Empresa Brasileira de Pesquisa Agropecuária. Monitoramento por satélites. Equipe Fast Air de Rally, 2013. Disponível em: http://www.rally.cnpm.embrapa.br. Acesso em: 10 abr. 2013.

EMBRATUR - Instituto Brasileiro de Turismo. Diretrizes para uma Política Nacional de Ecoturismo. Brasília, DF, 1994. 49 p.

GASPAR, M. T. P. Sistema aquífero Urucuia: Caracterização regional e propostas de gestão. Tese (Doutorado em Geografia) Universidade de Brasília, Brasília, 2006.

GÖSSILING, S. Ecotourism: A means to safeguard biodiversity and ecosystem functions? Ecological Economics, v.29, n.2, p.303-320, 1999.

IBAMA - Instituto Brasileiro do Meio Ambiente e dos Recursos Naturais Renováveis. Plano de ação para conservação do pato-mergulhão (Mergus octosetaceus). Série Espécies Ameaçadas, v.3, Brasília: IBAMA, 2006.

IBGE. Instituto Brasileiro de Geografia e Estatística. Evolução populacional. Brasília, 2015.2 Disponível em: http://www.ibge.gov.br/cidadesat/painel/painel.php? codmun=171270\#. Acesso em 12 mar. 2015.

IPCC - Intergovernmental Panel on Climate Change. Summary for policymakers, in climate change 2007: Impacts, adaptation and vulnerability. Contribution of Working Group II to the Fourth Assessment Report of the Intergovernmental Panel on Climate Change. Cambridge, UK: Cambridge University Press, 2007.

KINKER, S.M.S. Ecoturismo e conservação da natureza em Parques Nacionais. Coleção Turismo. Campinas: Papirus, 2002.

KRIPPENDORF, J. Sociologia do Turismo: para uma nova compreensão do lazer e das viagens. Rio de Janeiro: Civilização Brasileira, 1989, 236p.

LICKORISH, L.J.; JENKINS, C.L. Introdução ao turismo. Rio de Janeiro: Campus, 2000. 
MAY, R.M. Tropical arthropod species, more or less? Science, n.329, p.4142, 2010.

Millennium Ecosystem Assessment. Ecosystems and human well-being: Synthesis. Island Press, Washington, DC, 2005.

MMA - Ministério do Meio Ambiente do Brasil. Sistema nacional de Unidades de Conservação da Natureza - SNUC. v.5, Brasília: MMA, 2004.

NATURATINS - Instituto Natureza do Tocantins. Controle de visitação do Parque Estadual do Jalapão. Palmas: Naturatins, 2013.

PIERUCCINI, M. Os 10 episódios mais assistidos da década. 2009. Disponível em: http://www.cineseries.com.br/listas/os-10-episodios-maisassistidos-da-decada. Acesso em 9 mar. 2014

PIMM, S. L. Terras da terra: O que sabemos sobre o nosso planeta. Rio de Janeiro: Editora Planta, 2005.

SACHS, I. Ecodesenvolvimento: Crescer sem destruir. São Paulo: Vértice, 1986.

SANTOS, E.S. Dificuldades de implementação do ecoturismo no Parque Estadual do Cantão - TO. Monografia (Especialização Lato Sensu em Ecoturismo). Universidade Federal de Lavras, Lavras, 2007.

TAKAHASHI, L.Y. (1998). Caracterização dos visitantes, suas preferências e percepções e avaliação dos impactos da visitação pública em duas Unidades de Conservação do Estado do Paraná. Tese (Doutorado em Ciências Florestais). Universidade Federal do Paraná, Curitiba, 1998.

TAKASAGO, M.; GHILHOTO, J.J. M.; MOLLO, M.L.R.; ANDRADE, J.P. O potencial criador de emprego e renda do turismo no Brasil. Pesquisa e Planejamento Econômico. v.40, n.3 , 2010.

TOCANTINS. Agência de Desenvolvimento Turístico - ADTur. Plano de desenvolvimento integrado do turismo sustentável - PDITS. Produto 2. Polo do Jalapão. Diagnóstico Estratégico da Área e das Atividades Turísticas. Mai. 2014.

TOCANTINS. Secretaria do Planejamento e Meio Ambiente. Plano de manejo do Parque Estadual do Jalapão. Palmas, TO, 2003. 204p.

TRUMPER, K.; BERTZKY, M.; DICKSON, B.; VAN DER HEIJDEN, G.; JENKINS, M.; MANNING, P. The natural fix? The role of ecosystems in climate mitigation. A UNEP rapid response assessment. United Nations Environment Programme, UNEPWCMC, Cambridge, UK, 2009.

TV PRESS. SBT visita Jalapão com a equipe do Planeta Turismo. 2003. Disponível em: http://diversao.terra.com.br/gente/noticias/0,,Ol3520422El13419,00-SBT+visita+Jalapao+com+a+equipe+do+Planeta+Turismo.html. Acesso em 18 de Jun. 2013.

UNDESA - United Nations, Department of Economic and Social Affairs. World population prospects: The 2010 revision. New York, 2010.

WEARING, S.; NEIL, J. Ecoturismo: Impactos, potencialidades e possibilidades. Barueri: Manole, 2001. 
WEBVENTURE. Brasil é escolhido como melhor destino de Turismo de Aventura do mundo. Destino Aventura. 2008. Disponível em: http://webventureuol.uol.com.br/destinoaventura/n/brasil-e-eleito-o-melhordestino-de-aventura-do-mundo/24283. Acesso em 28 set. 2014.

WESTERN, D. Definindo Ecoturismo. In: LINDBERG, K.; HAWKINS, D. E. (Ed.), Ecoturismo: Um Guia para Planejamento e Gestão. v.3. São Paulo: Senac, 2001.

Erick da Silva Santos: Universidade Federal do Tocantins, Araguaína, TO, Brasil.

E-mail: erick.viagens@yahoo.com.br

Link para o currículo Lattes: http://lattes.cnpq.br/7855037350931891

Edilene Adelino Pequeno: Universidade Federal do Tocantins, Araguaína, TO, Brasil.

E-mail: edilenepequeno@gmail.com

Link para o currículo Lattes: http://lattes.cnpq.br/1274191689474470

Khalla Tupinamba Ribeiro: Universidade Federal do Tocantins, Araguaína, TO, Brasil.

E-mail:khallatupi@gmail.com

Link para o currículo Lattes: http://lattes.cnpq.br/9813409412364554

Letícia Lima de Freitas: Universidade Federal do Tocantins, Araguaína, TO, Brasil.

E-mail: leticialif@yahoo.com.br

Link para o currículo Lattes: http://lattes.cnpq.br/9895014743972619

Data de submissão: 27 de abril de 2015

Data de recebimento de correções: 29 de outubro de 2015

Data do aceite: 12 de novembro de 2015

Avaliado anonimamente 